Original Research Paper

\title{
Gas Atomization of Molten Metal: Part II. Applications
}

\author{
${ }^{1}$ Taher M. Abu-Lebdeh, ${ }^{1}$ Genaro Pérez-de León, \\ ${ }^{1}$ Sameer A. Hamoush, ${ }^{2}$ Roland D. Seals and ${ }^{2}$ Vincent E. Lamberti \\ ${ }^{I}$ Department of Civil, Architectural and Environmental Engineering, \\ North Carolina A\&T State University, Greensboro, NC, United States of America \\ ${ }^{2}$ Oak Ridge Y-12 National Security Complex, \\ Engineering Development Division, Oak Ridge-Tennessee, United States of America
}

Article history

Received: 09-04-2016

Revised: 12-04-2016

Accepted: 13-04-2016

Corresponding Author:

Taher Abu-Lebdeh

Department of Civil,

Architectural and

Environmental Engineering,

North Carolina A\&T State

University, Greensboro, NC,

United States of America

Email: taher@ncat.edu

\begin{abstract}
A numerical model was derived to obtain results for two alloys during the Gas Atomization (GA) method. The model equations and governing equations were implemented through the application of part I data. Aspects such as heat transfer, fluid mechanics, thermodynamics and law of motions were taken into account for the formulation of equations that take gas dynamics, droplet dynamics and energy balance or conservation into consideration. The inputs of the model include: Processing parameters such as the size of the droplets, characteristics of the metal alloy, initial temperature of the molten metal, properties and fractions of the atomization gas and the gas pressure. The outputs include velocity and thermal profiles of the droplet and gas. Velocity profiles illustrate the velocity of both droplet and gas, while thermal profiles illustrate cooling rate and the rate of temperature change of the droplets. The alloys are gamma-Titanium Aluminide $(\gamma$-TiAl) and Al-3003-O. These alloys were selected due to the vast amount of applications both can have in several industries. Certain processing parameters were held constant, while others were altered. The main focus of this study was to gain insight into which optimal parameters should be utilized within the GA method for these alloys and to provide insight into the behavior of these alloys.
\end{abstract}

Keywords: Gas Atomization, Molten Metal, Metal Powder, Heat Transfer, Droplet Dynamics

\section{Introduction}

Melt atomization has gained wide spread popularity due to its innovative ability of creating metal powder through atomization. Methods can range from spray, impulse and gas atomization. One study conducted by (Liu et al., 1995) utilized Nitrogen (N2) in the spray atomization of a of a Tantalum-2.5\% Tungsten metal alloy (Ta-2.5W). The authors sought to analyze and assess gas interactions in spray atomization of this alloy through the use of a lagrangian model composed of a fourth-order Runge-Kutta algorithm to solve for the droplet dynamics. A focus was placed on the momentum and heat transfer process of the atomization gas and droplets. An additional gas atomization experiment was conducted by (Wiskel et al., 2002) that utilized the Impulse Atomization (IA) technique. The IA method or technique is when a discontinuous jet of molten metal is formed by the mechanical acceleration of the molten liquid through an orifice in a nozzle plate by means of the plunger oscillating at low frequency and high amplitude. Once the stream exits the orifice plate, the distinct lengths break up into ligaments that spheroidize and cool as they fall in the solidification chamber. They constructed heat transfer models of molten metal droplets that were moving in a gas stream to gain a better understanding of gas atomization systems. Additionally, Henein (2010) produced an article that illustrated some similarities and differences of GA and IA. In this study completed, the same material was utilized in both GA and IA. The material was $\mathrm{Cu}-6 \mathrm{Sn}$ and in one example of a difference, the grain size of GA was significantly smaller than the one produced from IA when comparing both ingots. Furthermore, droplets created from GA are also smaller than ones created from IA, due to the high velocity atomizing gas. One similarity produced is that both processes had nearly the same value of porosity. 
Therefore, when comparing GA and IA, the better between the two is GA. GA is a better option due to the amount of control for desired results through the selection of powder chemistry, gas composition and powder size distribution as opposed to IA. This study will heavily focus on GA.

Initially in GA, a stream of molten metal is fragmented into micron-sized droplets by the impact of high-energy gas jets and the fragmentation properties are a result of relative velocity between the liquid and the atomization gas. GA is also a widely used technique of melt atomization because its ability to create high cooling rates. This happens because of the initially high relative velocity to the droplet as well as the fast-moving cold gas stream. Zheng et al. (2009a) conducted a GA process with numerical modeling and Zheng et al. (2009b) conducted a GA process by verifying the numerical model with an experiment. Equations and assumptions that were proposed through these studies were applied for this study. Some observations from the simulation were gas velocity reaches a maximum at the exit of the atomizer nozzle then decreases as an exponential decay as the flight distance increases, velocity of atomized droplets increases with increasing gas pressure and thermal behavior of the droplets is controlled by the processing conditions (atomizing gas composition, gas pressure, gas/melt mass flow ratio, melt superheat temperature and alloy composition). Within $\mathrm{GA}$, one factor of concern is the nozzle sized used. In experiment conducted by (Amirzadeh et al., 2013), they researched the effects of how altering the nozzle size changes the droplet diameter size, but a smaller nozzle diameter can cause blockage due to containments. They set out to produce molten metals droplets smaller than the nozzle diameter without altering the nozzle diameter. A piezoelectric droplet generator was utilized due to its success in previous experiments. Fang et al. (2008) were able to use three different sized nozzles to create four different sized molten Tin (Sn) droplets. The nozzles ranged from $0.177,0.254$ and $0.355 \mathrm{~mm}$ in diameter and they created droplets that were measured to be $0.18,0.35$, 0.60 and $0.75 \mathrm{~mm}$ in diameter. One key element that played a factor in the droplets sizes was oxidation and they were able to combat with the use of N2 flow.

The purpose of atomization and the different techniques is to create metal powder. Main focus of this study and research can be designated to the initial stages of the $3 \mathrm{D}$ printing process, which is creating and gaining more insight on the metal or alloy powder. Powder created can then be loaded and utilized to create 3D objects through layers of precision, which are then lowered to create depth. The last step is cooling the product and recycling unused powder. 3D printing can lead to roughly a $45 \%$ reduction in cycle time and cost (Tadjdeh, 2014).

\section{Methodology}

Gas atomization is a process that takes a melted sample of a metal alloy and creates a melt stream. The melt stream is then impinged with a powerful atomization gas that causes dispersion and creates particles. The particles or droplets then fall and cool as they make contact with a substrate or metal plate. Now due to the complexity of the process, a simulation can also serve as a resource to provide insight into different outcomes as opposed to an actual experimentation. A numerical model was built based on several aspects and equations such as heat transfer, fluid mechanics, thermodynamics, gas dynamics, droplet dynamics and energy balance that were proposed by (Zheng et al., 2009a) and part 1, of this two part study.

Based on the findings of previous studies, this simulation model incorporates the use of a close-type or confined design atomizer, since this model is solely using gas and not water, which would be an open-type or free fall design. Confined atomizers can produce a better distribution of fine powder through maximizing gas velocity and density once it makes contact with the molten metal. Other advantages include higher atomization efficiency and a greater consistency with the spray. Areas of concern include metal freezing prematurely within the delivery tube due to the effects of rapid solidification or heat extraction. Another disadvantage is the pressure can become positive or negative from the gas stream with the nozzle tip, which can cause an increase in metal flow rate or a blockage during actual experimentation. All applicable inputs include: Assumptions, aspects, gas properties, metal alloy properties, equations and constraints. Outputs can be designated as the velocity and thermal profiles, which illustrate the speed, droplet temperature and droplet cooling rate.

Heat exchange between the atomized particles and the surrounding medium are what the cooling rate depends on. The two mechanisms that cause this influence are radiation and convection. Radiation occurs from the energy released towards the atomizer chamber. Convection occurs into the cooling gas because of the manner of heat transfer amongst a solid surface and the surrounding liquid or gas that is in motion. Even though both mechanisms occur, convection is the major one and can be considered the most complex mechanism of heat transfer. One reason is due to the temperature gradient or the direction change and rate of the temperature that is exhibited in a set location. Another reason is the flow conditions that occur during GA. This model incorporates forced convection, due to the forced flow of fluid over a surface. Due to this forced convection, the heat that is removed from the droplets surface equals the change in the droplets temperature (Cengel and Ghajar, 2014). 


\section{Results}

The results section focuses on obtaining data on Al alloys under different processing parameters. Due to the previous completed studies that fall under the GA process, the two key parameters that are altered or viewed during this section will be the gas composition and droplet diameter size. It is indicative that these two are the most predominant factors on influencing the cooling rate. Other processing parameters such as gas atomization pressure and melt superheat temperature will be held constant. Even though gas atomization pressure and melt superheat temperature can impact the velocity and thermal profile of the alloy droplets, the influence is not as great as the gas composition and droplet diameter size. The gas atomization pressure will be $2.76 \mathrm{MPa}$, per the study conducted by (Zheng et al., 2009a) that stated pressures exceeding this amount do not have a great impact on the cooling rate. The melt superheat temperature will be different and will be discussed in the subsequent sections below. The gas composition will consist of $100 \%-\mathrm{He}, 100 \%$-Ar and $50 \% \mathrm{Ar}-50 \%$ He mixture for the gas atomization. Even though $\mathrm{He}$ is a far more superior gas for GA, these parameters are chosen to see the reaction of this selection on the selected metal alloys. Droplet diameter sizes will range from 5 to $50 \mu \mathrm{m}$, based on the research from previous studies that indicate smaller sized droplets produce higher cooling rates and less time to solidify than larger sized ones. Results obtained from the model are found in following sections for each alloy.

\section{Metal Alloy Selection}

Aluminum is the world's most abundant metal and the third most common element after oxygen and silicon. Both metal alloys comprise of $\mathrm{Al}$ and other elements. Versatility of $\mathrm{Al}$ allows it to be one of the most widely used metals. The first alloy selected is gamma-Titanium Aluminide ( $\gamma$-TiAl). Some traits of $\gamma$ TiAl include: Light-weight, low ductility, as well as resistance to oxidation, heat and corrosion. Several applications for it are found in the automotive and aerospace industries for devices such as aircraft turbine engines and blades (Voskoboinikov et al., 2013). The second alloy is Al-3003-O, which contains manganese and the $\mathrm{O}$ signifies the temper. This means it is annealed and the alloy has been heated beyond the point of the recrystallization temperature, which causes the alloy to have lowest tensile strength condition (UAC, 2013). Properties of this alloy include: Medium strength and good formability as well as good corrosion resistance. Since this alloy can be considered one of the most common general purpose alloys, the uses are vast. Some of these applications include: Pressure vessels, storage tanks, home appliances, gutters and heat exchangers (Mick, 2015). Both alloys represent numerous applications and industries, which justifies the selection of the two for the model. The properties implemented within the model for each alloy selected were obtained through the previous studies and research. Emissivity, density and melt superheat temperature of the alloys $\gamma$-TiAl and Al-3003-O, respectively, are listed as follows: The emissivity are values 0.5 and 0.4 , the density values are $3636,2730 \mathrm{~kg} / \mathrm{m}^{3}$ and the melt superheat temperatures are 1885 and $1373 \mathrm{~K}$. The specific heat capacity will be utilized for both, due to fact that it is a function of the droplet temperature. $\gamma$-TiAl

Obtaining the velocity profile for the three different gas compositions are found below in Fig. 1 to 3 . It is evident that as the amount of He increases, the gas velocity and droplet velocity increases as well. The droplet velocity for the larger sized droplets (35 and 50 $\mu \mathrm{m})$ within Fig. 3 illustrate that after reaching a maximum velocity, the gradual decline of velocity as shown in Fig. 1 and 2, do not occur. These figures also illustrate the disparity between a small $(5 \mu \mathrm{m})$ and large $(50 \mu \mathrm{m})$ droplet velocity. Larger sized droplets have a greater area and volume, therefore are able to resist the acceleration and deceleration drag forces that are imposed on the droplets during Gas Atomization (GA).

The figures below show how altering gas composition and droplet diameter size can affect the droplet temperature. Figure 4 to 6 indicate that pure $\mathrm{He}$ gas significantly improves the cooling rate of the droplets. For example, comparing the cooling rate for a $5 \mu \mathrm{m}$ droplet at $100 \%$-Ar to a $5 \mu \mathrm{m}$ droplet at $100 \%$ He illustrates that a $100 \%$-He droplet cools at a much faster rate. The $100 \%$-He droplet takes roughly 0.17 $\mathrm{ms}$ and the $100 \%$-Ar droplet takes $1.2 \mathrm{~ms}$ to cool to the same temperature. The mixture of $\mathrm{He}-\mathrm{Ar}$ and $\mathrm{Ar}$ are not as successful in providing a higher decrease in droplet temperature as He. Additionally, smaller droplets portray a greater amount of decrease in temperature than larger ones due to the lesser amount of area and volume.

Figure 7 through 9 show the influences that gas composition and droplet diameter have on droplet cooling rate. Pure He proves to cool droplets faster in an allotted ranged of time as opposed to pure Ar or the mixture of the two. For example, a $50 \mu \mathrm{m}$ at $100 \%-\mathrm{Ar}$ has a maximum cooling rate of roughly $2.5^{*} 10^{\wedge} \mathrm{K} / \mathrm{s}$ but staggers as time elapses, but the $50 \mu \mathrm{m}$ at $100 \%$ $\mathrm{He}$ has a maximum cooling rate of roughly $1.5 * 10^{\wedge} 6$ $\mathrm{K} / \mathrm{s}$ and as time elapses, it reaches a lower rate compared to the $100 \%$-Ar within the same time frame of 0 to $4.5 \mathrm{~ms}$. 


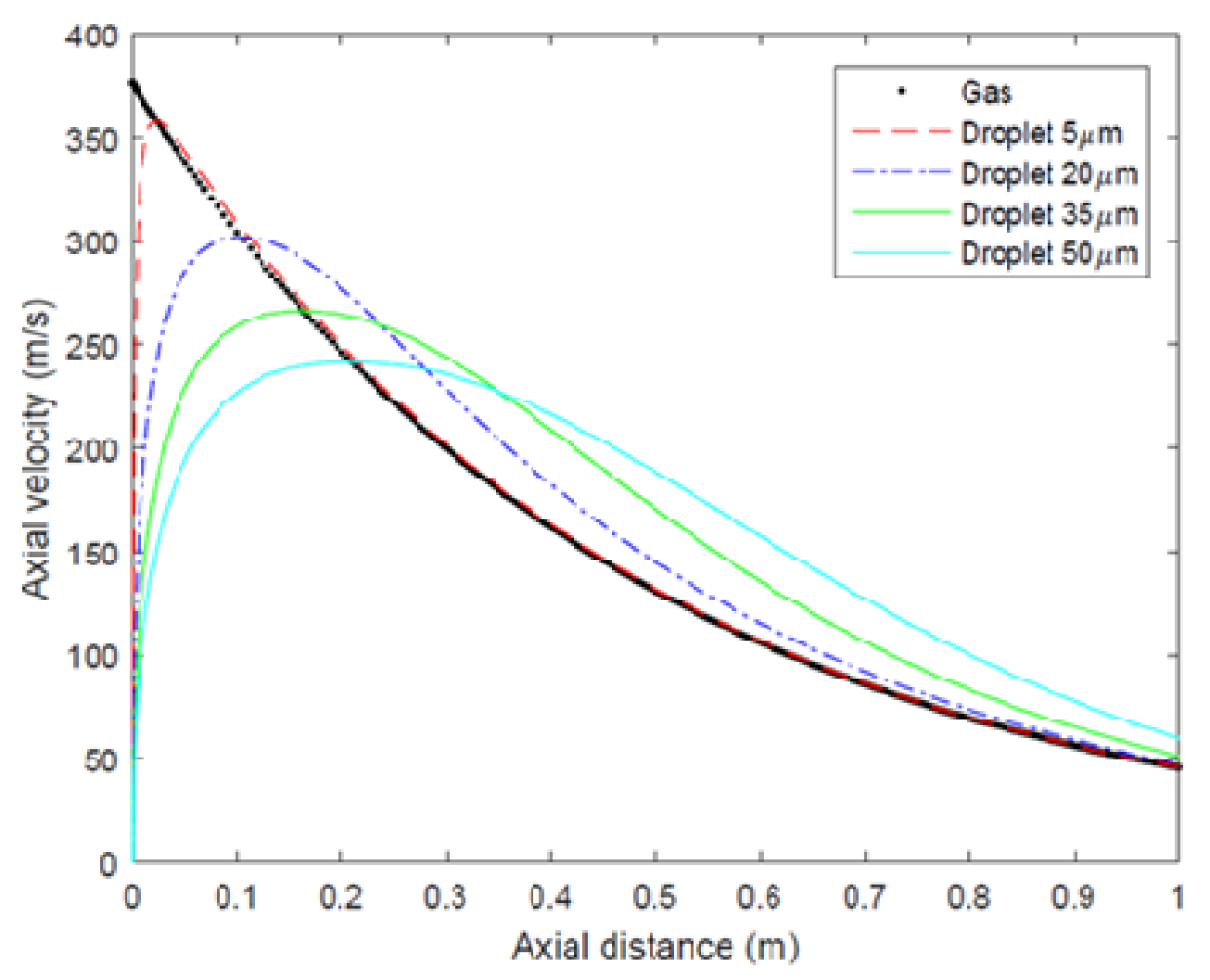

Fig. 1. Velocity profile at $100 \%-\mathrm{Ar}(\gamma$-TiAl) versus distance

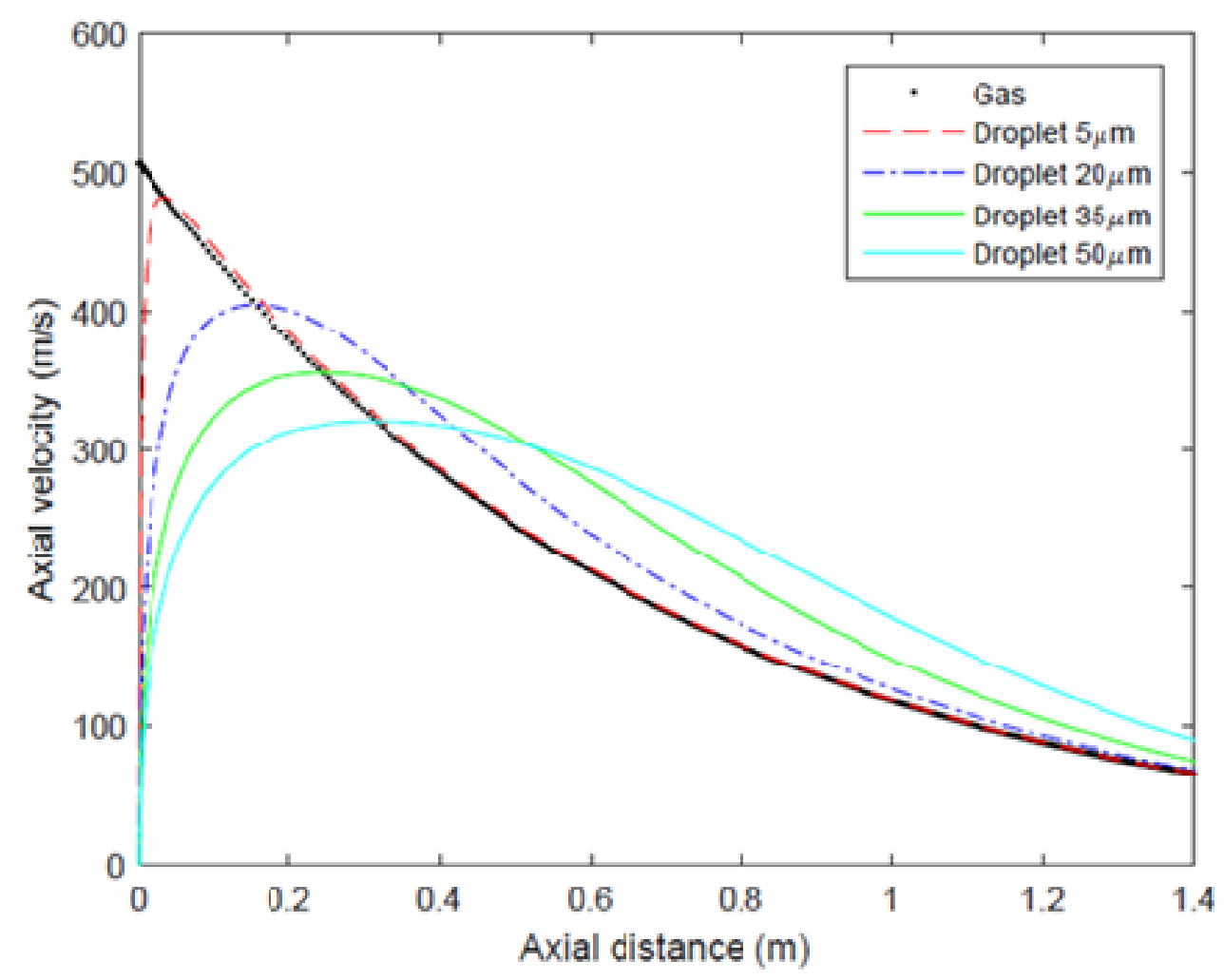

Fig. 2. Velocity profile at 50\%-He and 50\%-Ar $(\gamma-\mathrm{TiAl})$ versus distance 


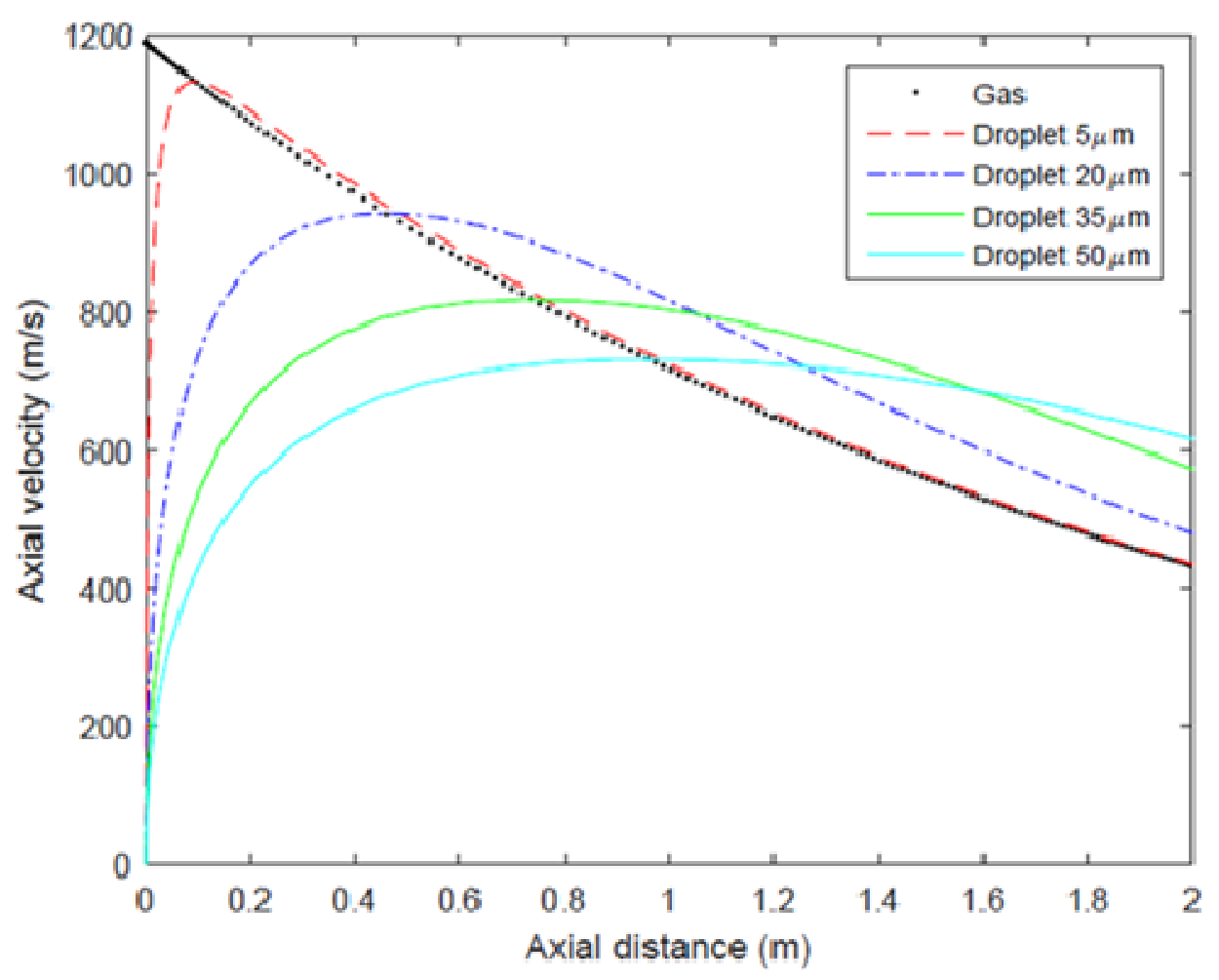

Fig. 3. Velocity profile at $100 \%-\mathrm{He}(\gamma$-TiAl) versus distance

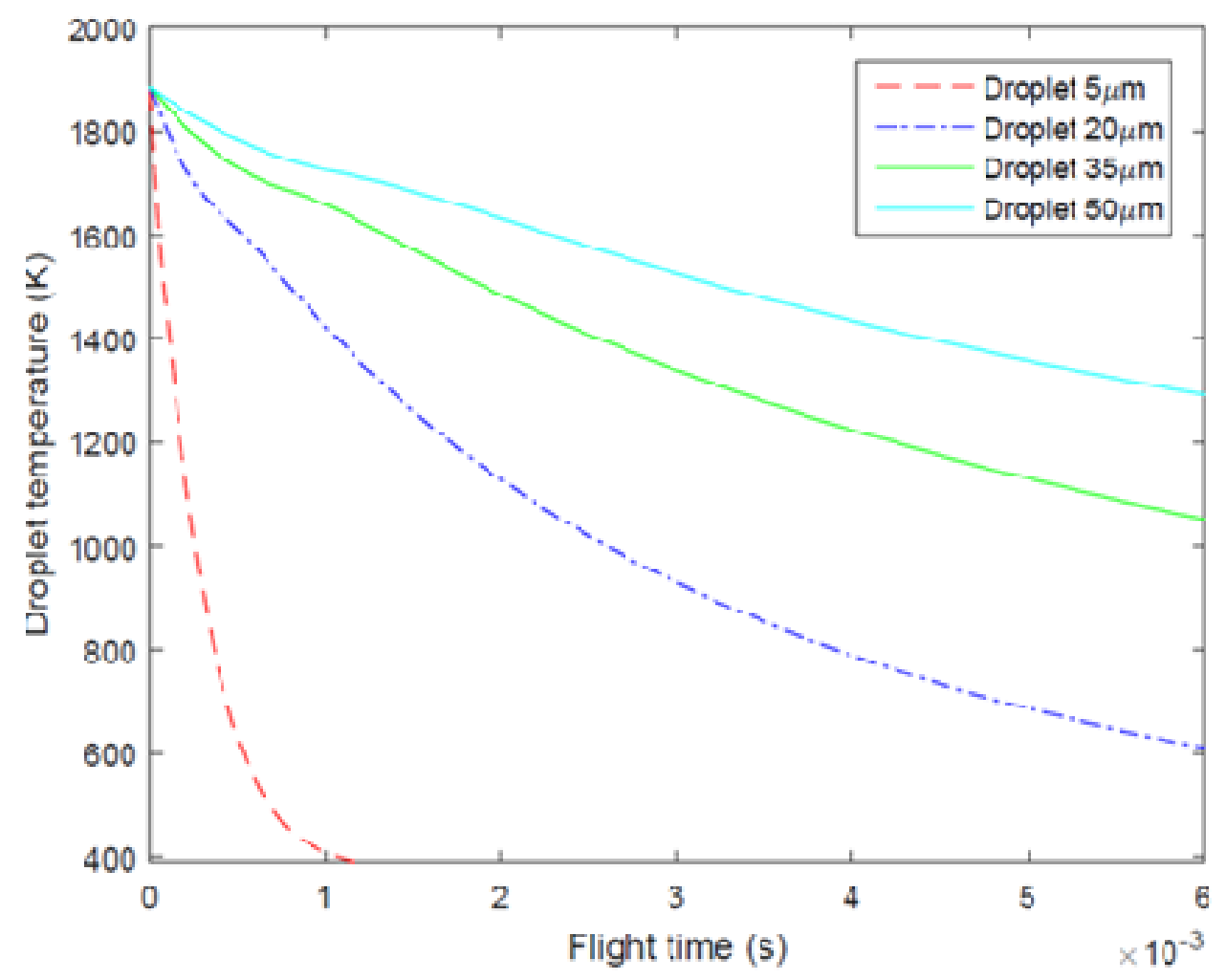

Fig. 4. Thermal profile of alloy at $100 \%$-Ar $(\gamma$-TiAl $)$ versus time 


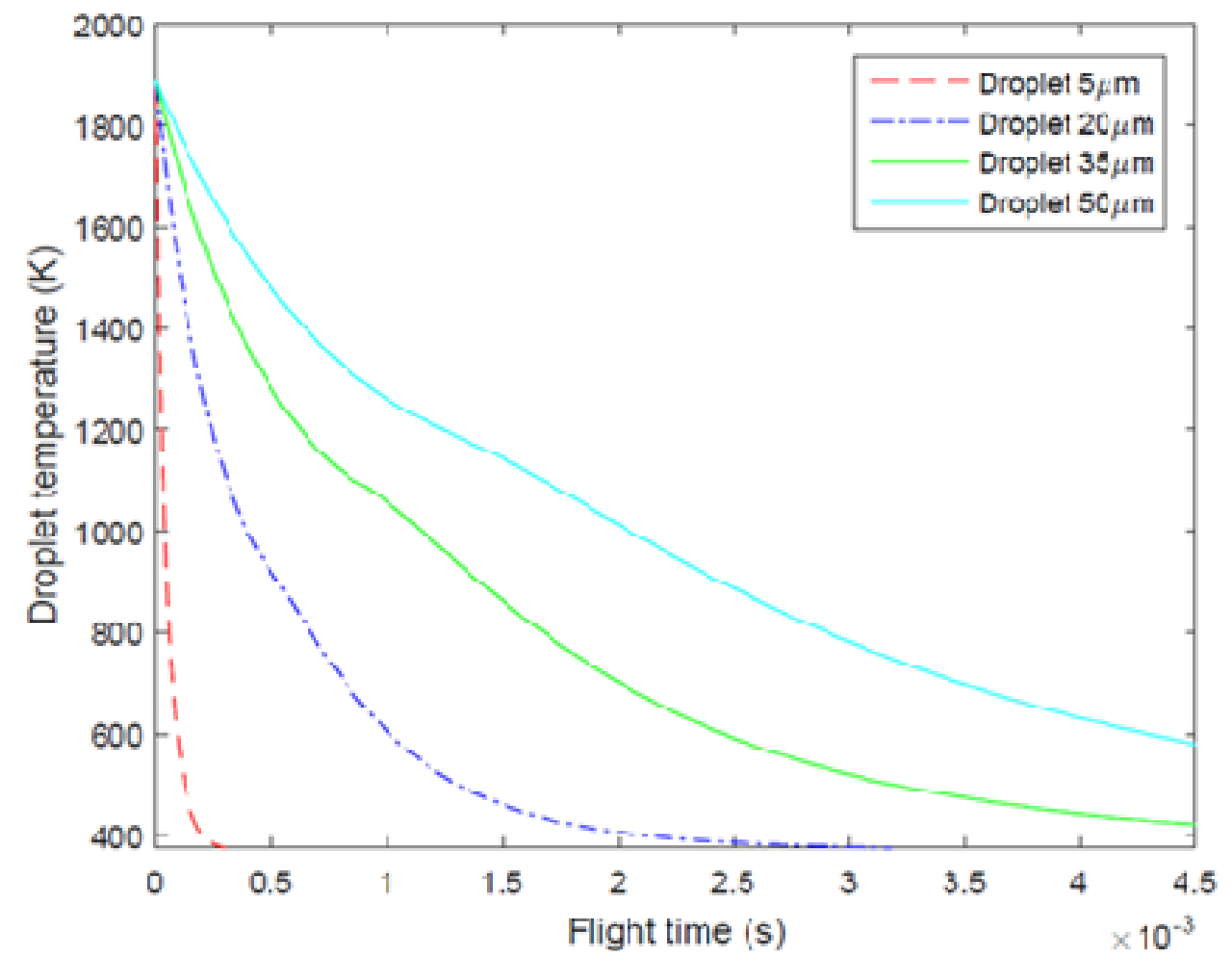

Fig. 5. Thermal profile of alloy at 50\%-He and 50\%-Ar ( $\gamma$-TiAl) versus time

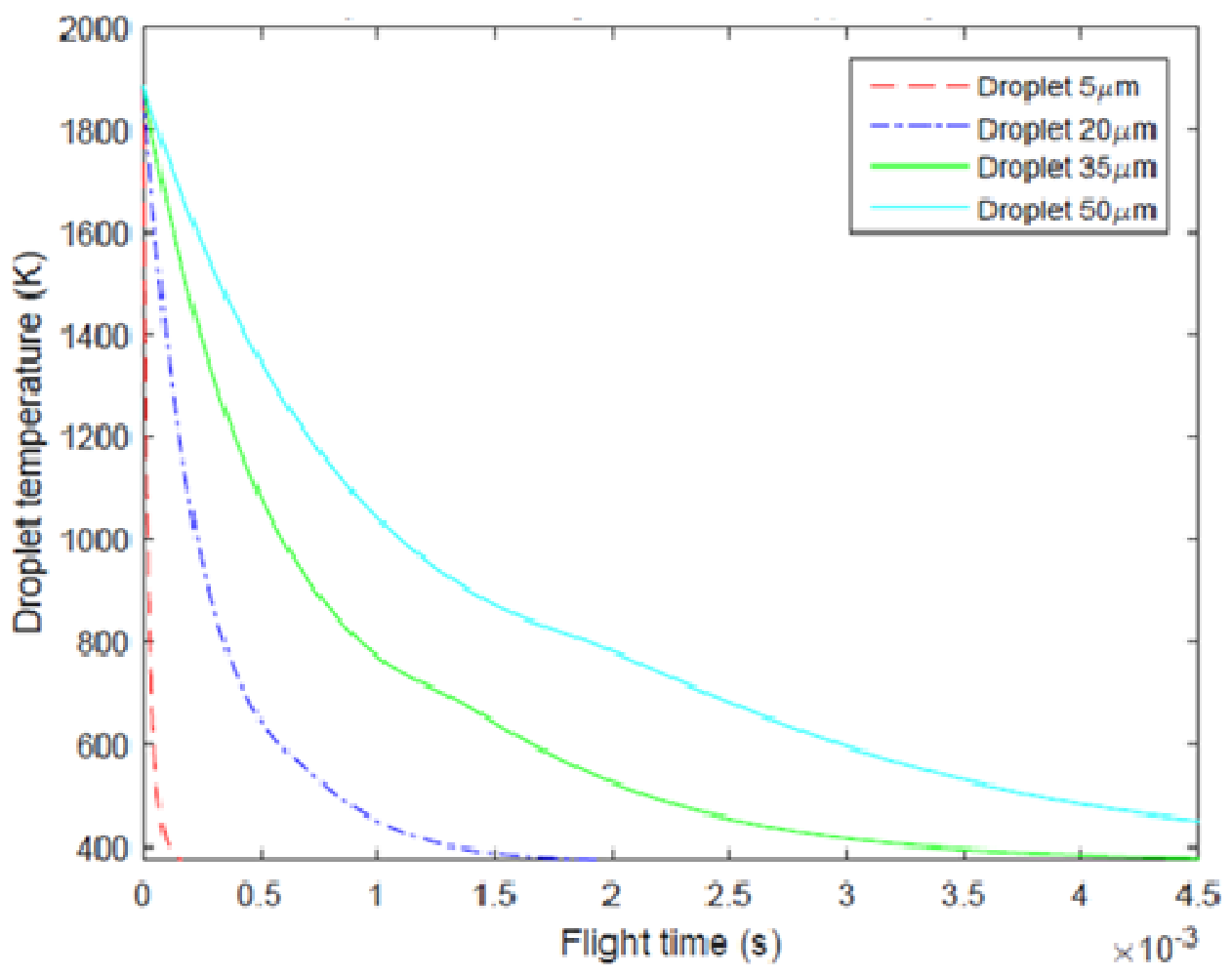

Fig. 6. Thermal profile of alloy at $100 \%$-He $(\gamma$-TiAl) versus time 


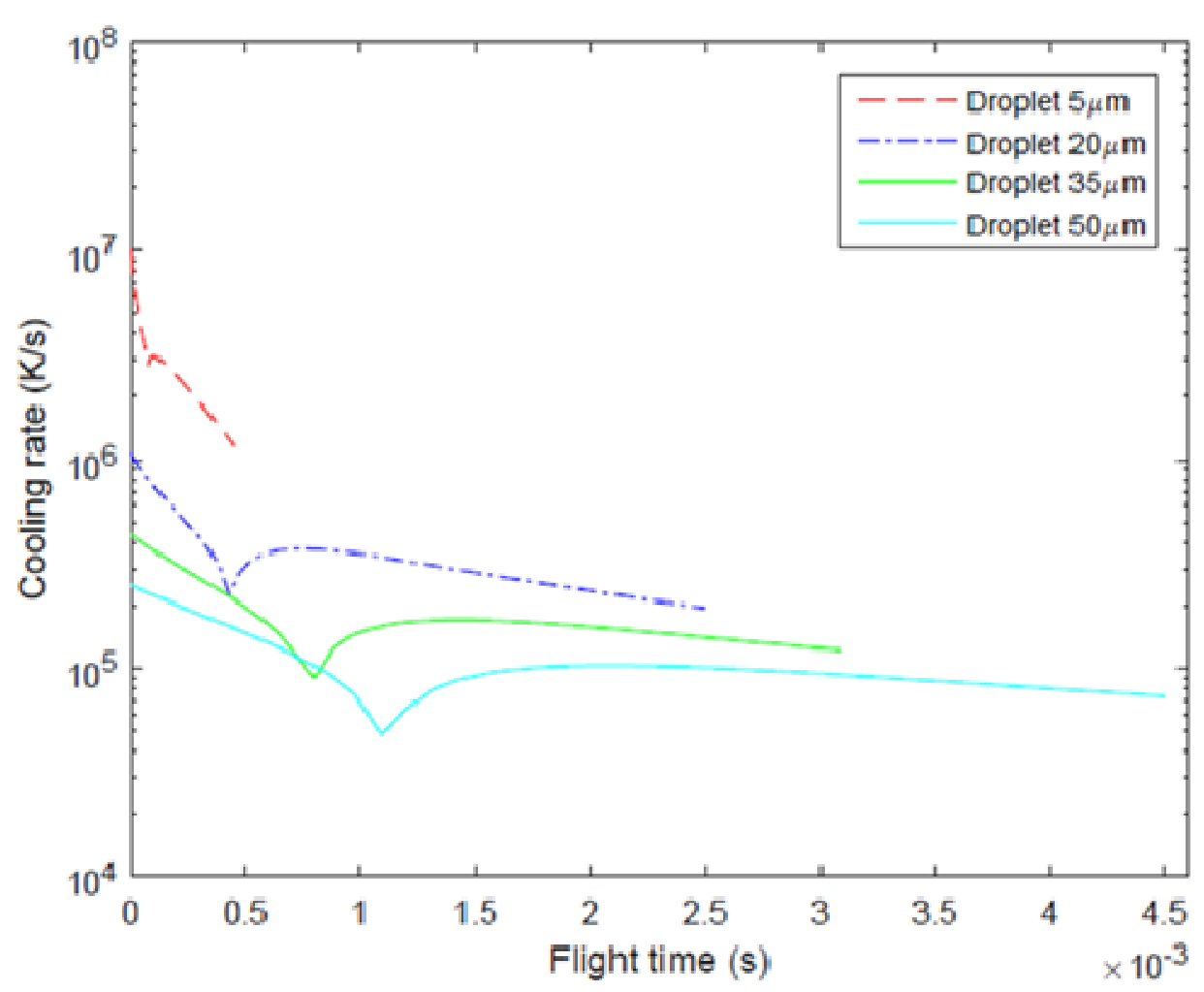

Fig. 7. Cooling rate at $100 \%-\mathrm{Ar}(\gamma-\mathrm{TiAl})$ versus time

\section{Al-3003-O}

Velocity profiles of Al-3003-O are located here in Fig. 10 to 12 . Once again, it is clear that due to the consistent processing parameters for each alloy, the gas velocity remains the same. In addition, comparing both alloys, it is clear that a higher He content creates greater droplet velocities, even though the gas velocities for both alloys are the same. Gas velocities are as follows:

$100 \%$-Ar gas velocity is approximately $375 \mathrm{~m} \mathrm{sec}^{-1}$, $50 \%$-He and $50 \%$-Ar gas velocity is nearly $500 \mathrm{~m} \mathrm{sec}^{-1}$ and $100 \%-\mathrm{He}$ gas velocity is approximately $1200 \mathrm{~m}$ $\mathrm{sec}^{-1}$. Furthermore, the higher the He content and smaller the size contributes to a higher velocity. The figures below represent the selection of droplets ranging in size from 5 to $50 \mu \mathrm{m}$, with gas composition changing from 100\%-Ar, 50\%-He and 50\%-Ar and $100 \%$-He. Results show that as the gas composition increases in the amount of $\mathrm{He}$, the temperature decline increases as well. This is evident to due to the fact that He has smaller molar mass and density compared to Ar. In addition, He has a significantly higher specific heat capacity than Ar. or example, He has a specific heat capacity of $5278 \mathrm{~J} /(\mathrm{kg} * \mathrm{~K})$ versus Ar $521 \mathrm{~J} /\left(\mathrm{kg}^{*} \mathrm{~K}\right)$, which essentially means that a greater form of energy (heat) is required to raise the temperature of $\mathrm{He}$, which means He does not have a rapid change of energy as compared to Ar. He proves to be a better coolant than Ar because of this extra heat required to raise the temperature of He. He absorbs a greater amount of heat than Ar, from the melt stream of droplets which leads to a greater form of reduction of heat for the droplets, therefore producing a greater amount of temperature decline for droplets atomized by $\mathrm{He}$ as opposed to those from Ar. Figure 13 to 15 illustrate the accuracy of this occurrence. Also, smaller droplets cool faster because the energy (heat) from the smaller droplet is much less than that of a larger droplet. Larger droplets take a longer amount of time for the heat to leave them and transfer to the atomization gas. As it is evident from the previous cooling rate for previous alloy, the same pattern of cooling rate occurs here. Figure 16 to 18 represent this pattern. Another key difference between the atomization gases of $\mathrm{He}$ and $\mathrm{Ar}$ are the thermal conductivity values. He has a thermal conductivity of $0.15 \mathrm{~W} /\left(\mathrm{m}^{*} \mathrm{~K}\right)$ while Ar has one of $0.02 \mathrm{~W} /(\mathrm{m} * \mathrm{~K})$. This means that $\mathrm{He}$ is more efficient in transferring energy (heat), which essentially means He receives the heat generated from the droplets at a faster rate than $\mathrm{Ar}$ which causes them to cool faster. Taking consideration of the comparison of droplet velocity between $\gamma$-TiAl and Al-3003-O, it is suggestive that a higher velocity leads to higher quantities of cooling rate. 
Taher M. Abu-Lebdeh et al. / American Journal of Engineering and Applied Sciences 2016, 9 (2): 334.349 DOI: 10.3844/ajeassp.2016.334.349

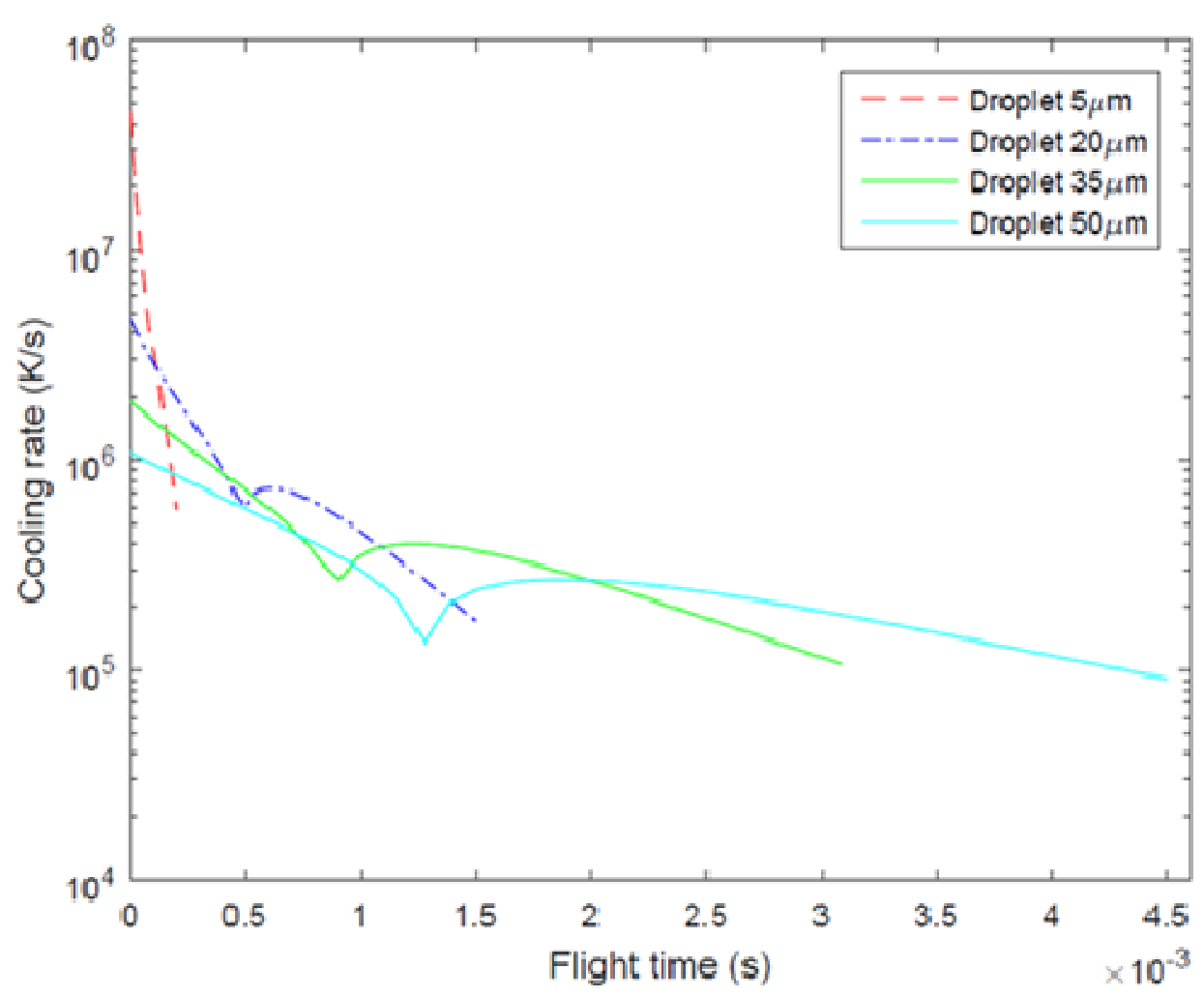

Fig. 8. Cooling rate at 50\%-He and 50\%-Ar $(\gamma$-TiAl $)$ versus time

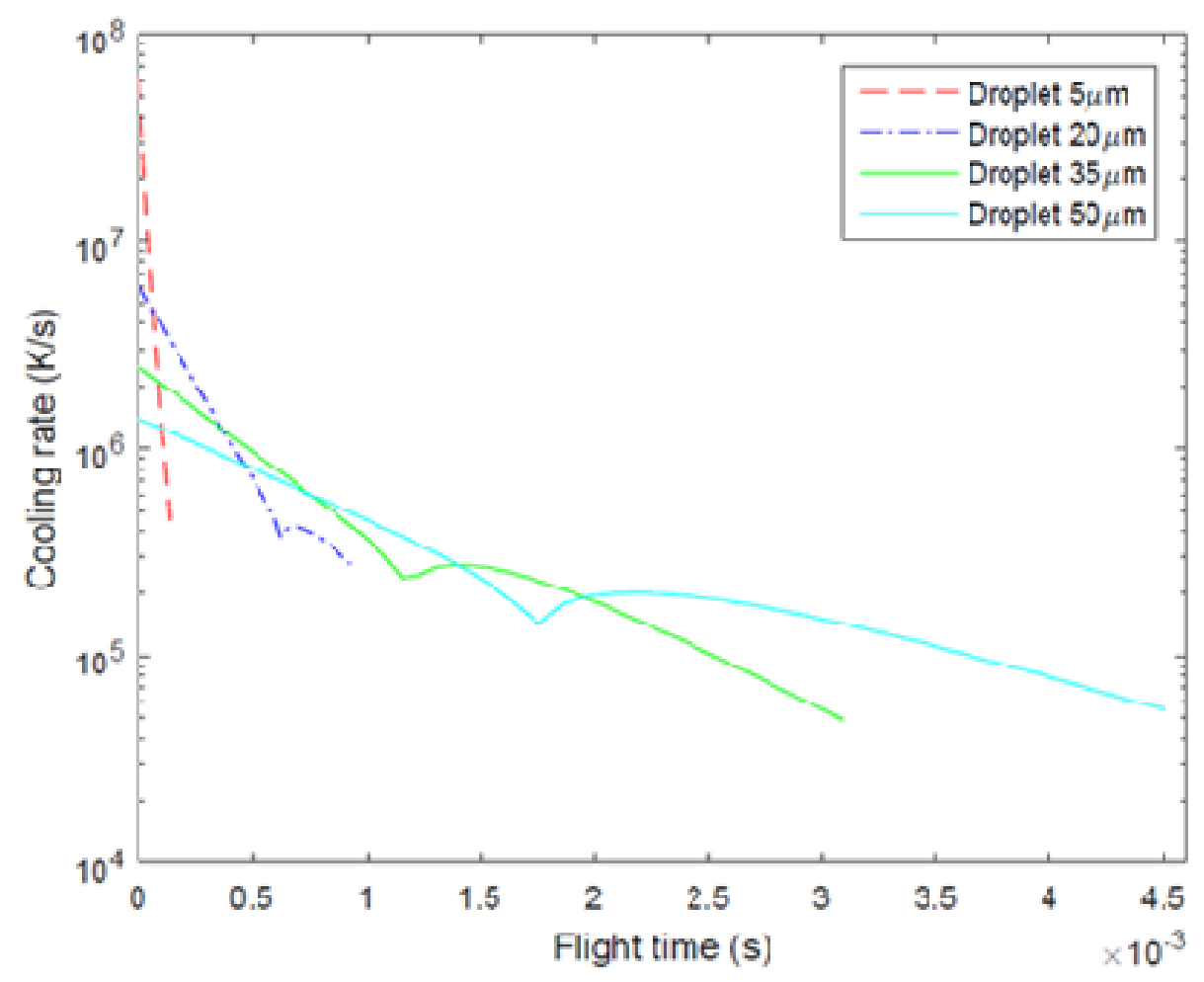

Fig. 9. Cooling rate at $100 \%-\mathrm{He}(\gamma$-TiAl) versus time 


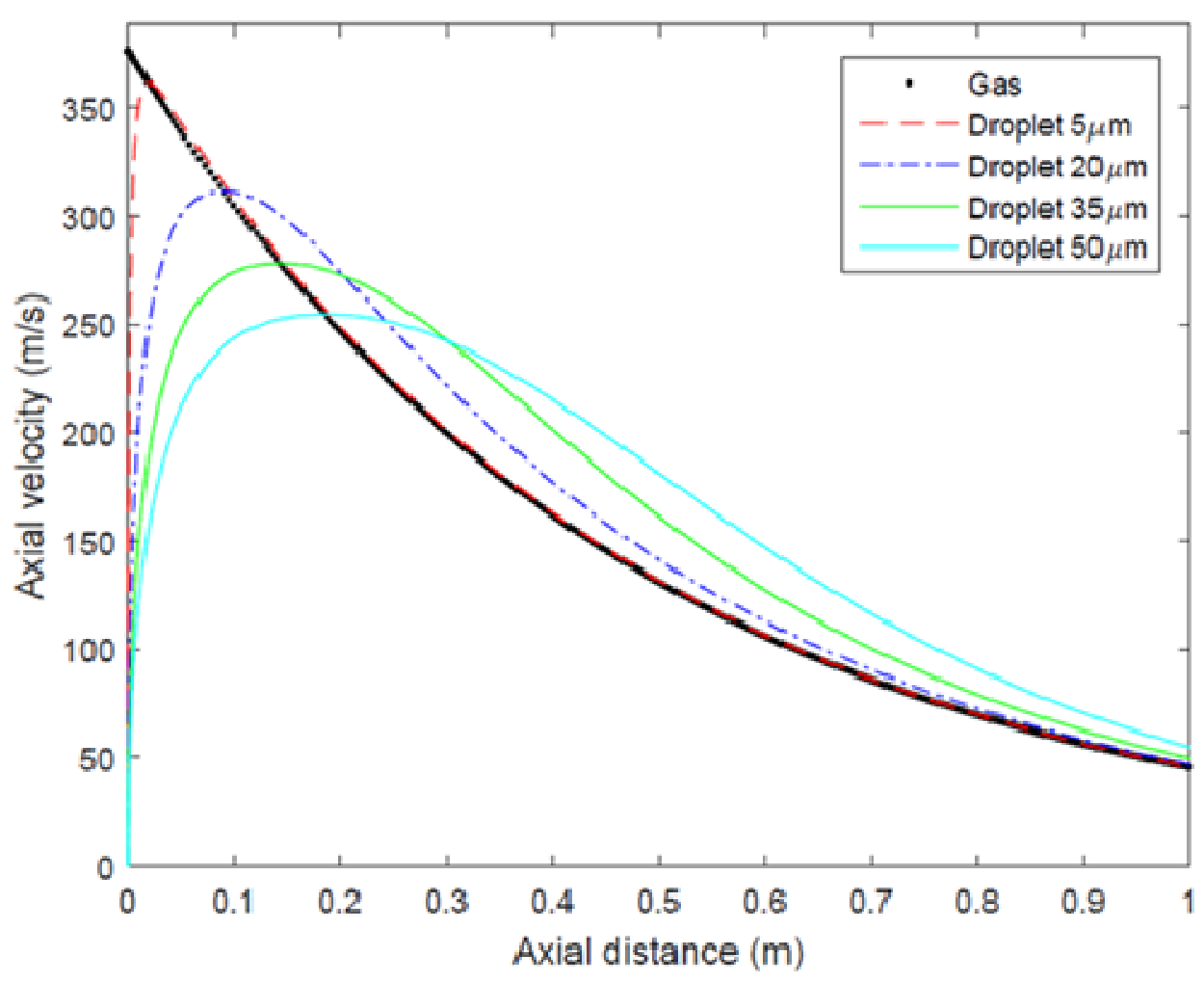

Fig. 10. Velocity of alloy at 100\%-Ar (Al-3003-O)

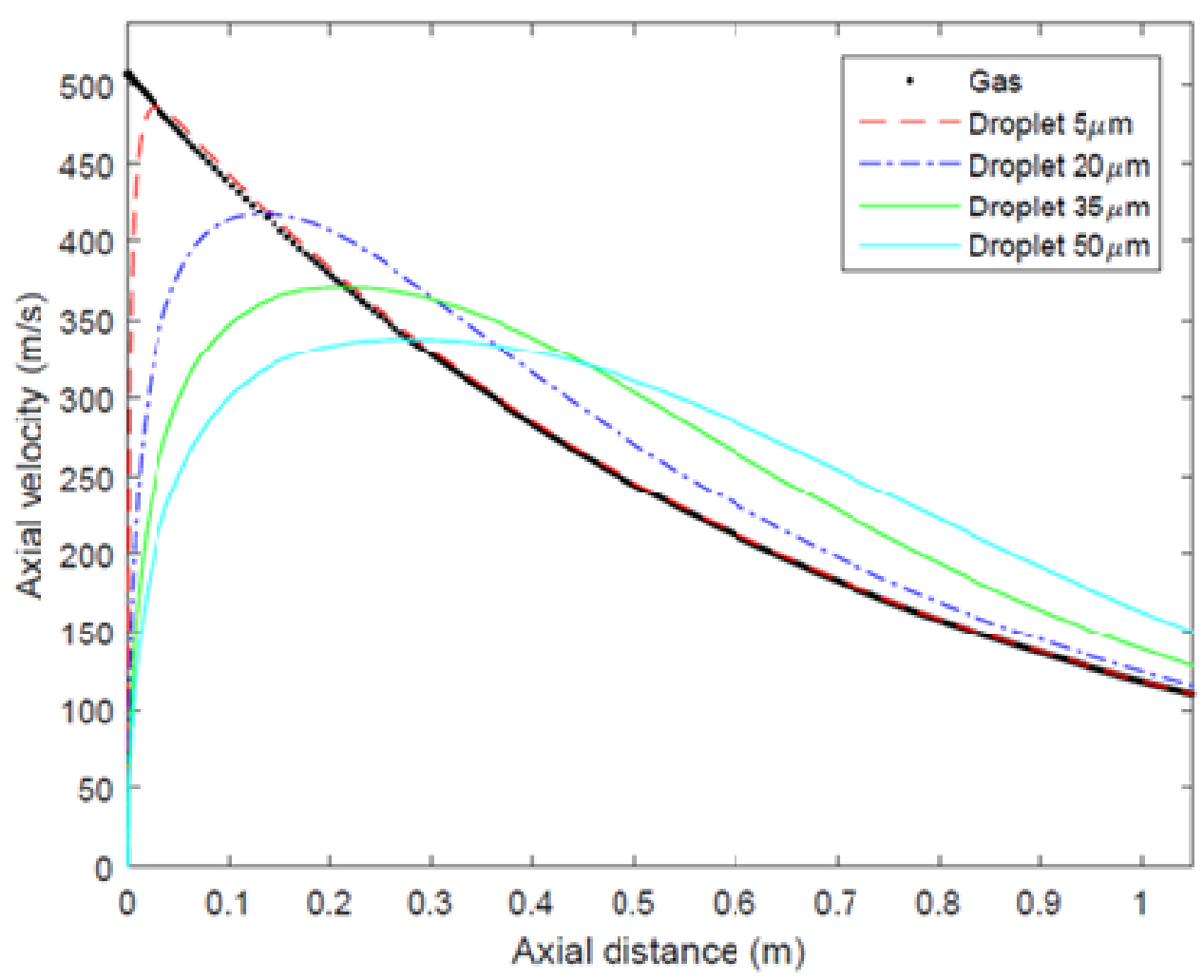

Fig. 11. Velocity profile of alloy at 50\%-He and 50\%-Ar (Al-3003-O) 


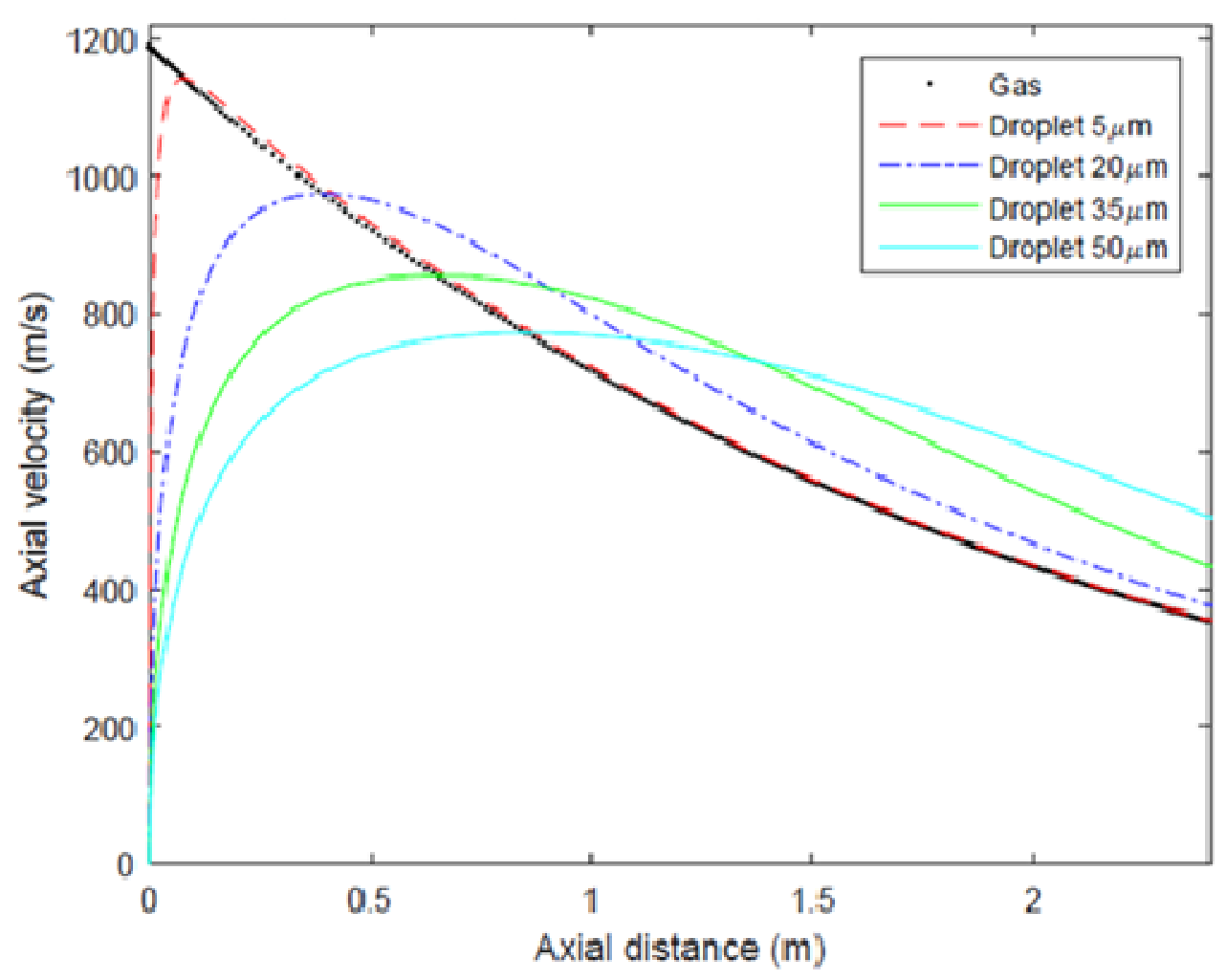

Fig. 12. Velocity of alloy at $100 \%-\mathrm{He}(\mathrm{Al}-3003-\mathrm{O})$

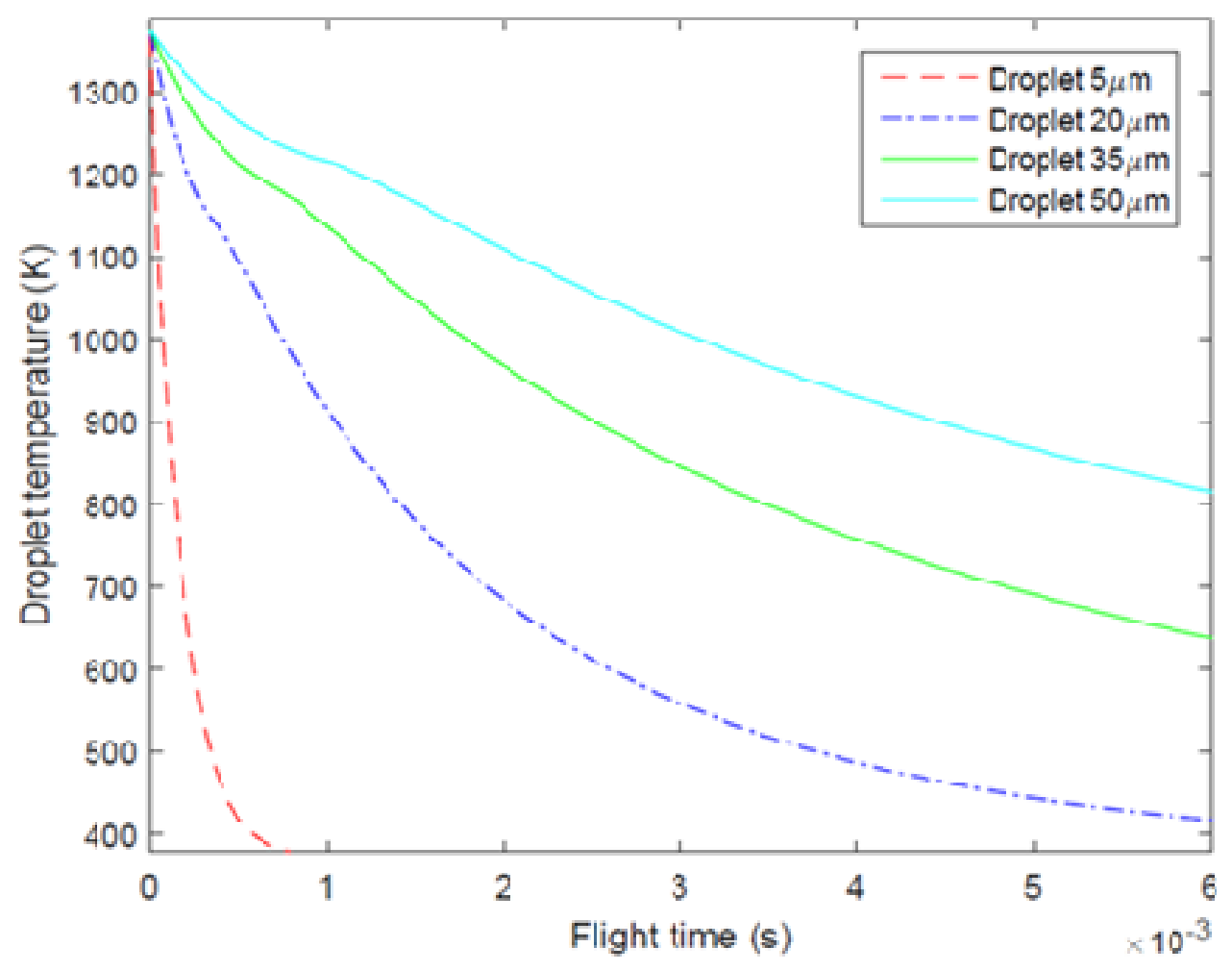

Fig. 13. Thermal profile at $100 \%-\operatorname{Ar}(\mathrm{Al}-3003-\mathrm{O})$ 


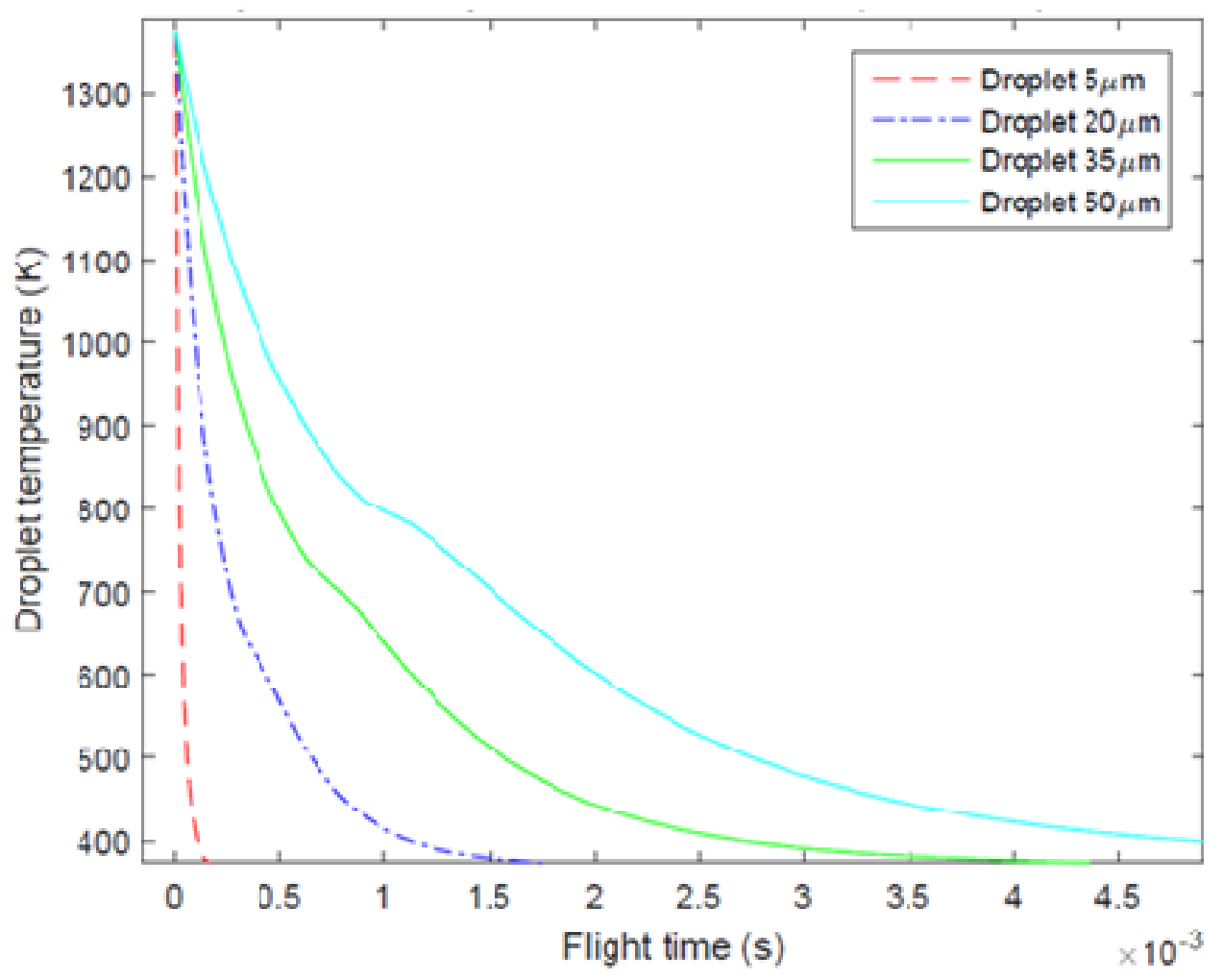

Fig. 14. Thermal profile of alloy at 50\%-He and 50\%-Ar (Al-3003-O)

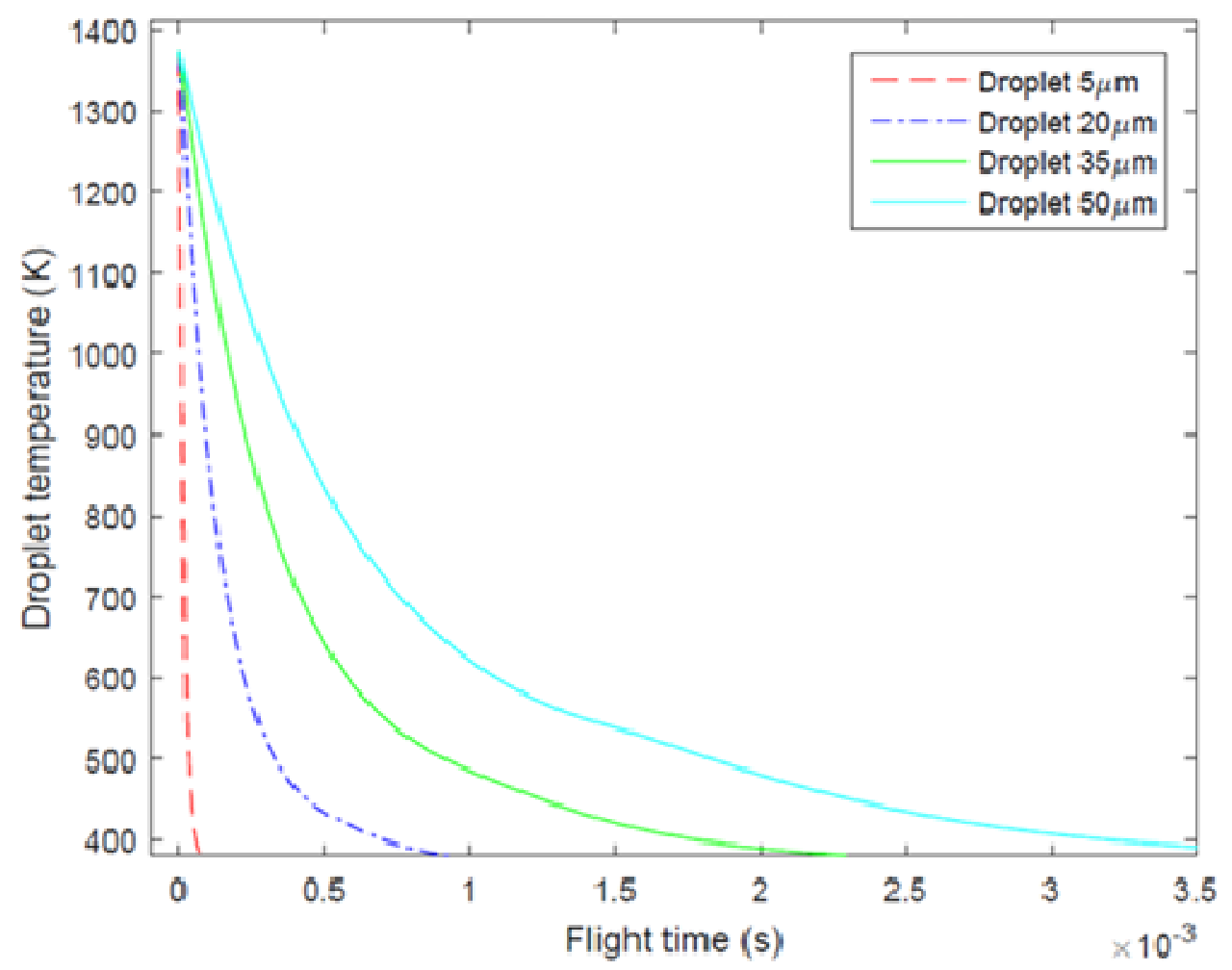

Fig. 15. Thermal profile of alloy at 100\%-He (Al-3003-O) 
Taher M. Abu-Lebdeh et al. / American Journal of Engineering and Applied Sciences 2016, 9 (2): 334.349 DOI: 10.3844/ajeassp.2016.334.349

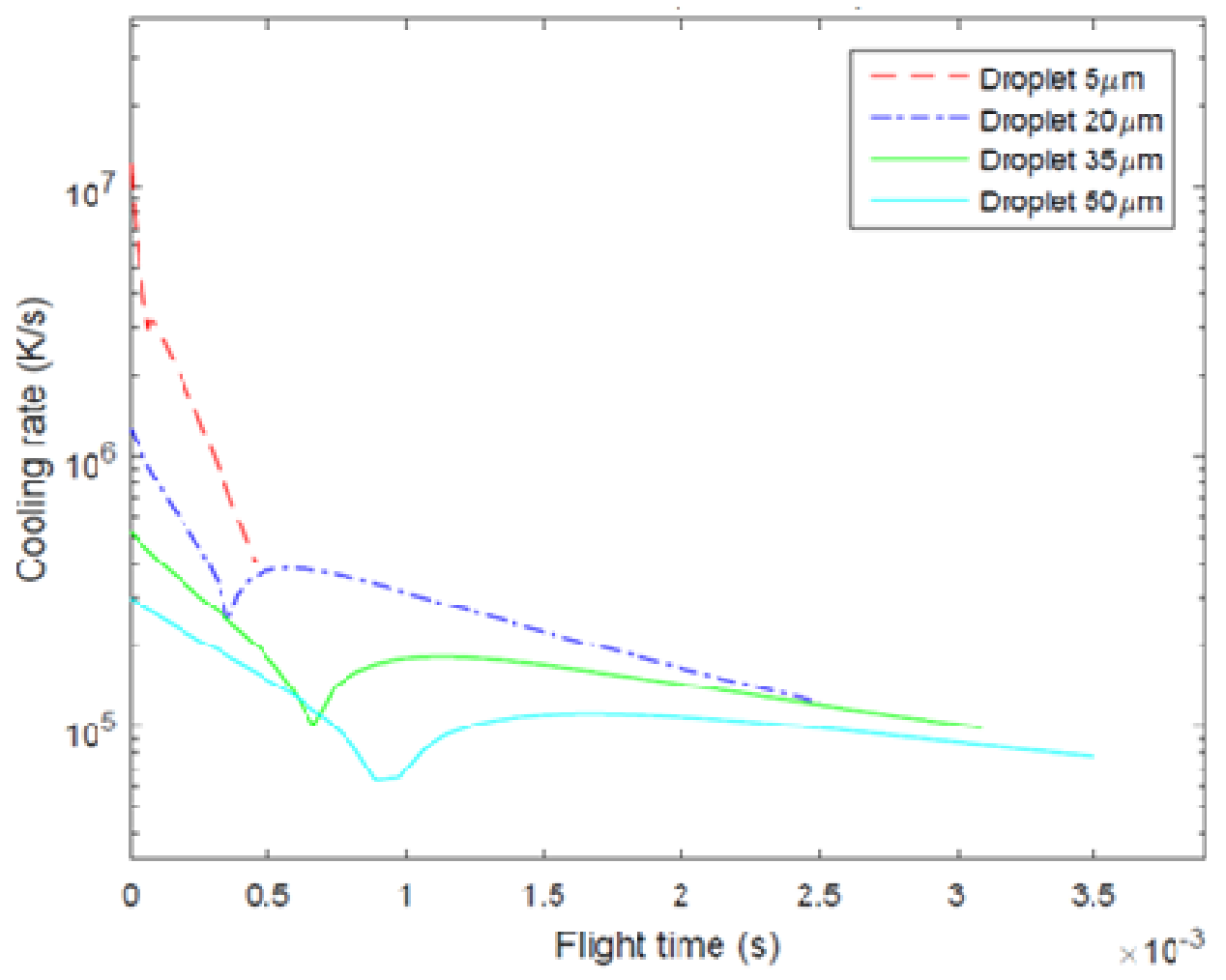

Fig. 16. Cooling rate at $100 \%-\mathrm{Ar}(\mathrm{Al}-3003-\mathrm{O})$

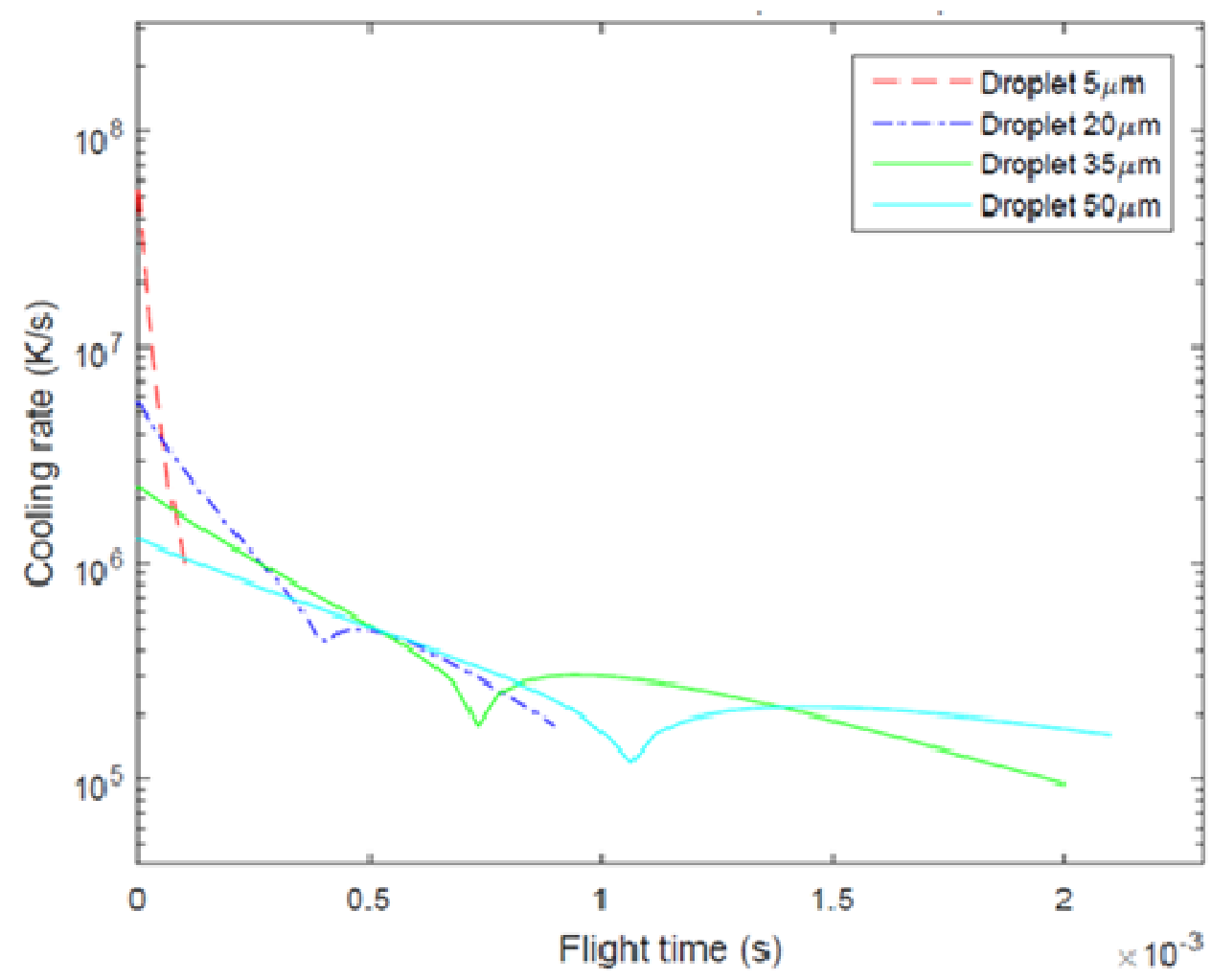

Fig. 17. Cooling rate at 50\%-He and 50\%-Ar (Al-1100-O) 


\section{Discussion}

The alloys selected for study in this research have an abundant amount of applications in numerous industries such as the home appliances, automotive and aerospace industry. Each alloy used in a GA process can add greater amount of use for the public. Therefore, alloy selection is left to the user and the desired applications of the metal powder produced from the alloy. Cultivation of previous studies, research and this model suggest that pure He serves as the best atomization gas when compared to Ar. He is superior and efficient in its ability to absorb the heat that is released from the melt stream of droplets throughout the GA process. Figure 19 to 22 further solidify why $\mathrm{He}$ is superior and why $\mathrm{He}$ and smaller or fine droplets are better suited for GA and quicker cooling rates. Viewing the results below illustrate there is a clear distinction.

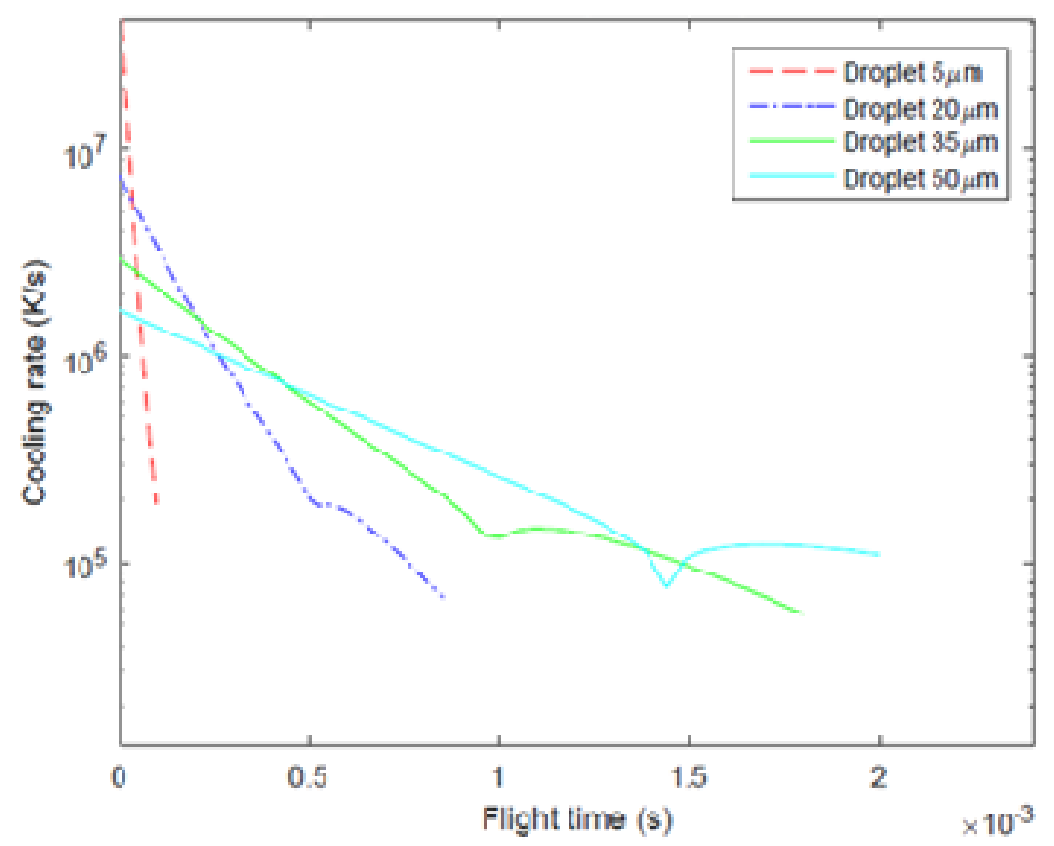

Fig. 18. Cooling rate at $100 \%-\mathrm{He}(\mathrm{Al}-3003-\mathrm{O})$

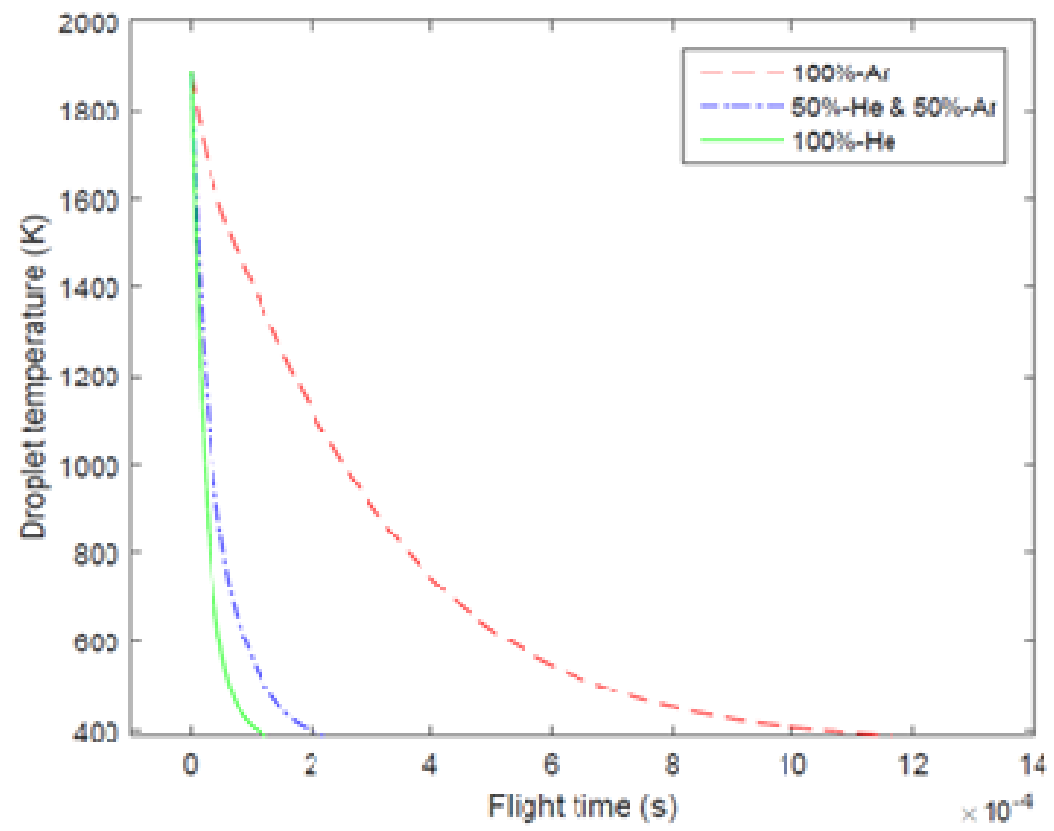

Fig. 19. Thermal profile comparison of alloy $\gamma$-TiAl versus time for $5 \mu \mathrm{m}$ 


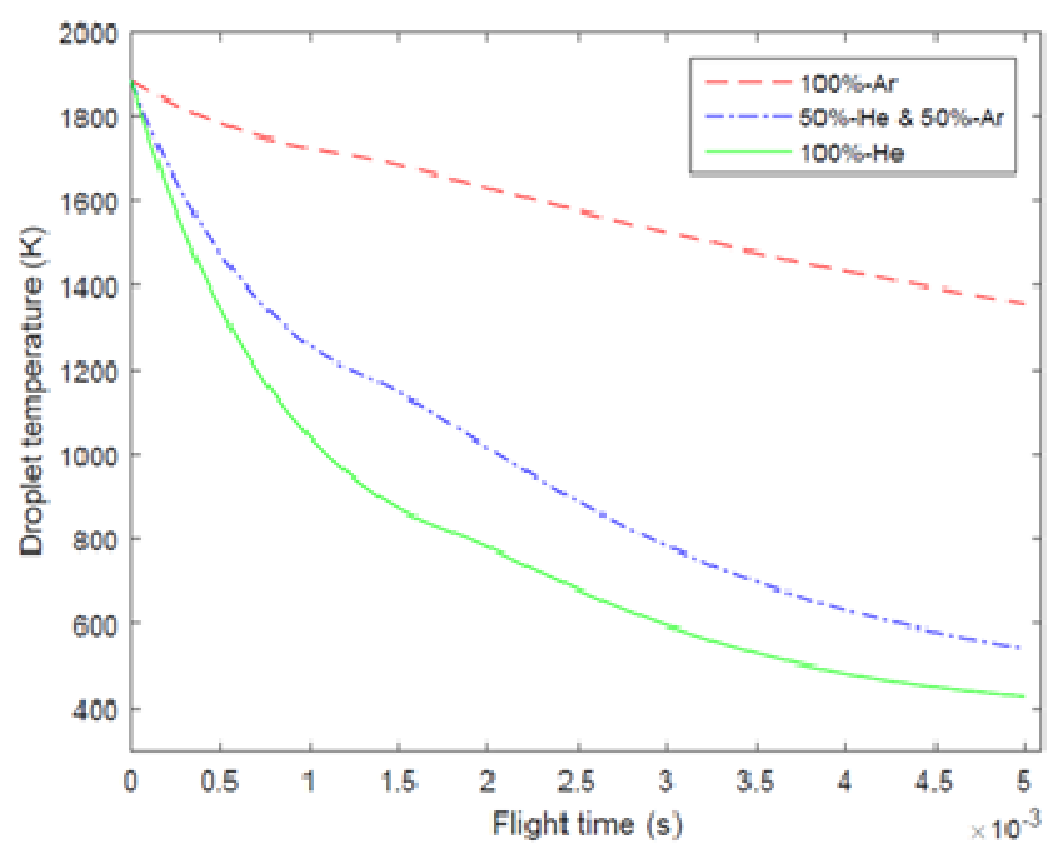

Fig. 20. Thermal profile comparison of alloy $\gamma$-TiAlversus time for $50 \mu \mathrm{m}$

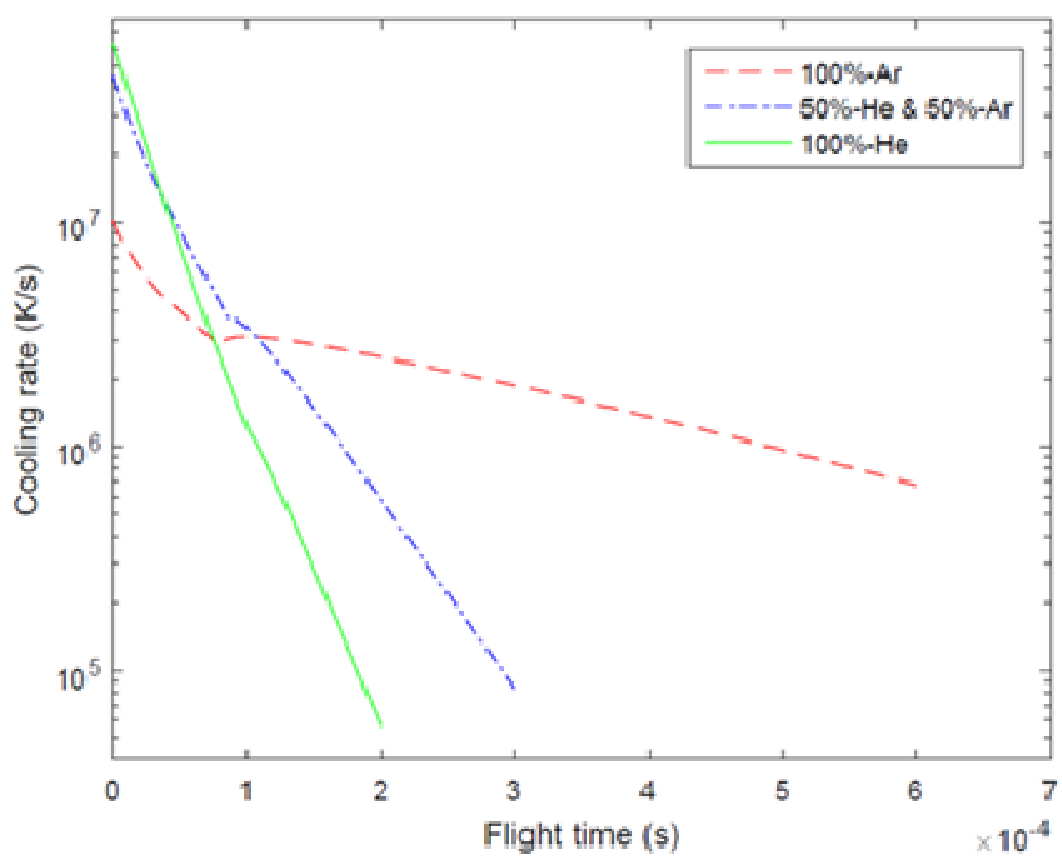

Fig. 21. Cooling rate comparison of alloy $\gamma$-TiAl versus time for $5 \mu \mathrm{m}$

For example, when viewing Fig. 18, it is evident that $100 \%$ He produces a sharper decrease in temperature when compared to $100 \%$-Ar by a difference of approximately $1.035 \mathrm{~ms}$. When comparing Fig. 18 and 19, it is also clear the vast difference of what the decrease in temperature is when comparing 5 and $50 \mu \mathrm{m}$. For example, comparing the 5 and $50 \mu \mathrm{m}$ droplet diameter size, when employed with a gas atomization of $100 \%-\mathrm{He}$, produces roughly a difference of $4.9 \mathrm{~ms}$. These examples of time difference may be minuscule, but in terms of mass production and additive manufacturing, this can lead to a savings in cost and time needed to produce objects, widgets, or pieces for later use in application within the industry. Therefore, utilizing He and finer sized droplets are suggested for GA. 


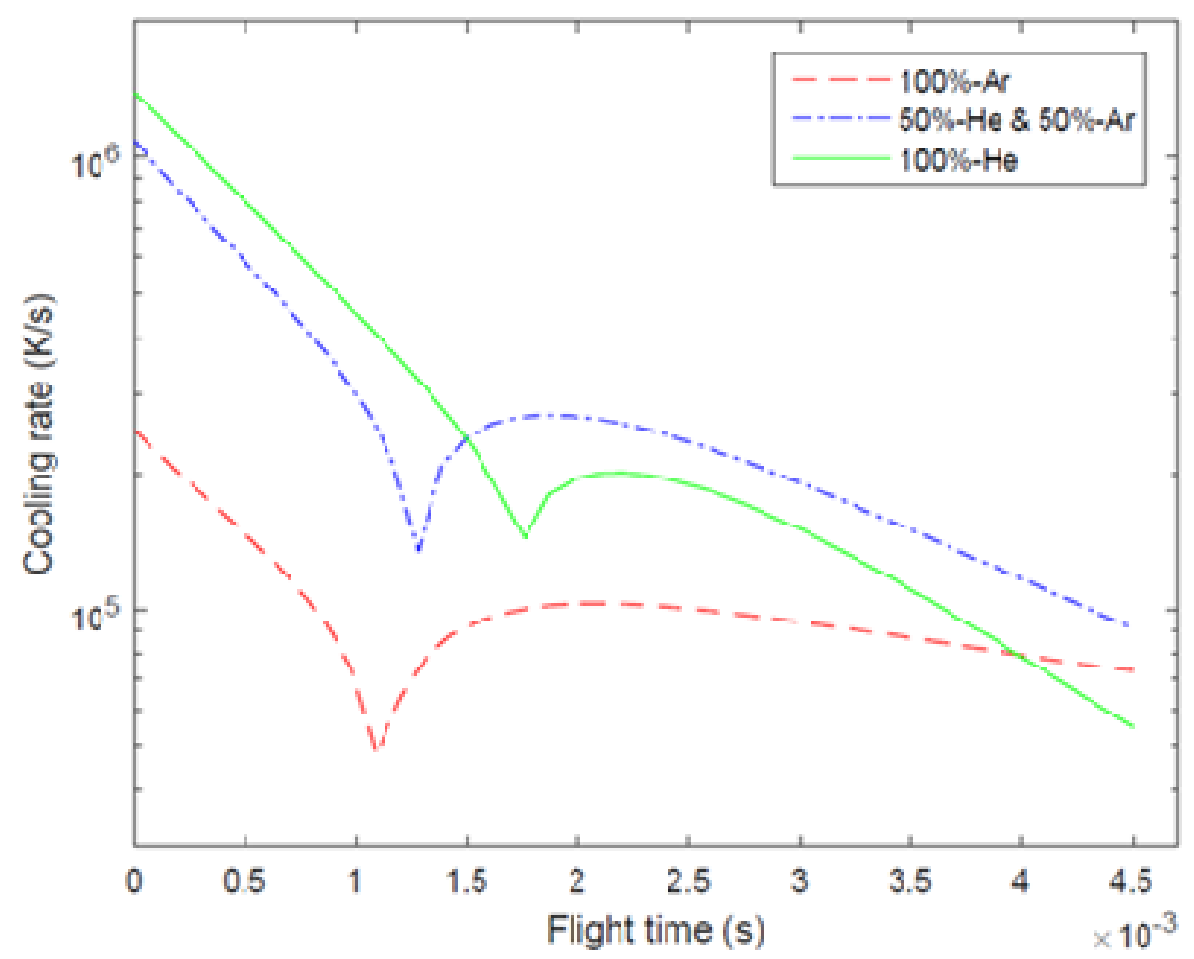

Fig. 22. Cooling rate comparison of alloy $\gamma$-TiAl versus time for $50 \mu \mathrm{m}$

\section{Conclusion}

Gas Atomization (GA) and the production of metal powder is an innovative method that stills need a larger spectrum of information when it comes to processing parameters and deciding which metal alloy to use as the melt stream. The nature of this modeling has garnished more understanding of gas atomization and alloys through the application of analyzing previous studies and applying those aspects to formulate new results. However, in order to fully validate the results and observations of this model on new alloys, an experimental validation is necessary as future research. Completing experimentation on the alloys selected for this study can test the accuracy and precision of the model, as well as add depth to the findings and conclusions.

A numerical model was built through the application of governing equations and aspects that utilized factors such as gas dynamics, droplet dynamics, energy balance, heat transfer, fluid mechanics and thermodynamics. An explicit RungeKutta formula and numerical differentiation formulas were applied as well. The model was able to produce new results for a set of different alloys. Emphasis was placed on gaining knowledge and greater insight on the selection of utilizing optimal processing parameters and droplet behavior during the GA process. Model proved to be successful in producing results that are comparable to part I results. Through the application of creating this model several conclusions were reached:

- As the droplet diameter size increases: The velocity, droplet temperature change and cooling rate of the droplet decreases. Also, optimal parameters include utilizing smaller or fine droplets because smaller droplets have less inertia and size

- Helium is a far more superior atomization gas when compared to Argon, when selecting the gas composition. Helium is able to absorb the heat and facilitate the transfer of heat much quicker than the other two. This trait allows for the droplets to cool faster and produce more efficient results

- Optimal alloy selection is left to the user and desired results for application of the powder

- An experimental validation or study is necessary as future research to compare results from this model

\section{Acknowledgment}

This paper summarizes the findings of a research work funded by the National Nuclear Security Administration (NNSA). Any findings and recommendations expressed in this paper are those of the authors.

\section{Funding Information}

The work reported here was financially supported by the National Nuclear Security Administration (NNSA). 


\section{Author's Contributions}

Taher M. Abu-Lebdeh: Participated in all modeling, data-analysis and contributed to the writing of the manuscript.

Genaro Pérez-de León: Participated in modeling, dataanalysis and contributed to the writing of the manuscript.

Sameer A. Hamoush: Participated in modeling plan, data-analysis and contributed to the writing of the manuscript.

Roland D. Seals: Participated in modeling plan, dataanalysis and contributed to the writing of the manuscript.

Vincent E. Lamberti: Participated in all modeling, data-analysis and contributed to the writing of the manuscript.

\section{Ethics}

All rights reserved. No part of this publication may be reproduced or transmitted in any form without permission in writing from the publisher or authors.

\section{References}

Amirzadeh, A., M. Raessi and S. Chandra, 2013. Producing molten metal droplets smaller than the nozzle diameter using a pneumatic drop-on-demand generator. Exp. Thermal Fluid Sci., 47: 26-33. DOI: $10.1016 /$ j.expthermflusci.2012.12.006

Cengel, Y.A. and A.J. Ghajar, 2014. Heat and Mass Transfer: Fundamentals and Applications. 5th Edn., McGraw-Hill Education, New York, pp: 992.

Fang, M., S. Chandra and C.B. Park, 2008. Building three-dimensional objects by deposition of molten metal droplets. Rapid Prototyp. J., 14: 44-52. DOI: $10.1108 / 13552540810841553$
Henein, H., 2010. Why is spray forming a rapid solidification process? Warum ist Sprühkompaktieren ein Schnell-Erstarrungsprozess? Materialwissenschaft Werkstofftechnik, 41: 555-561. DOI: 10.1002/mawe. 201000642

Liu, H., R.H. Rangel and E.J. Lavernia, 1995. Modeling of droplet-gas interactions in spray atomization of Ta-2.5W alloy. Mater. Sci. Eng. A, 191: 171-184. DOI: 10.1016/0921-5093(94)09631-6

Mick, J., 2015. Analysis: iPhone 6S May Use 6013 Aluminum Alloy Instead of 7000 Series Alloys 2016.

Tadjdeh, Y., 2014. 3D printing promises to revolutionize defense, aerospace industries. Nat. Defense Magaz., 98: 20-25.

UAC, 2013. Chemical composition and properties of aluminum alloys. United Aluminum Corporation.

Voskoboinikov, R.E., G.R. Lumpkin and S.C. Middleburgh, 2013. Preferential formation of Al self-interstitial defects in $\gamma$-TiAl under irradiation. Intermetallics, 32: 230-232. DOI: $10.1016 /$ j.intermet.2012.07.026

Wiskel, J., H. Henein and E. Maire, 2002. Solidification study of aluminum alloys using impulse atomization: Part I: Heat transfer analysis of an atomized droplet. Canadian Metallurgical Quarterly, 41: 97-110. DOI: 10.1179/cmq.2002.41.1.97

Zheng, B., Y. Lin, Y. Zhou and E.J. Lavernia, 2009a. Gas atomization of amorphous aluminum: Part I. Thermal behavior calculations. Metallurgical Mater. Trans. B, 40: 768-778. DOI: 10.1007/s11663-009-9276-5b

Zheng, B., Y. Lin, Y. Zhou and E. Lavernia, 2009b. Gas atomization of amorphous aluminum powder: Part II. Experimental investigation. Metallurgical Mater. Trans. B, 40: 995-1004. DOI: $10.1007 / \mathrm{s} 11663-009-9277-4$ 